\title{
Correlation of mechanical factors and gallbladder pain
}

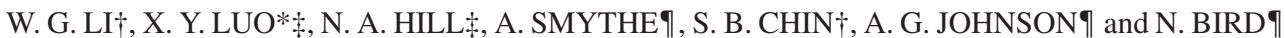

\author{
$†$ Department of Mechanical Engineering, University of Sheffield, Sheffield S1 3JD, UK \\ \$Department of Mathematics, University of Glasgow, Glasgow G12 8QW, UK \\ ๆ Academic Surgical Unit, Royal Hallamshire Hospital, Sheffield S10 2JF, UK
}

(Received 2 July 2007; revised 18 October 2007; in final form 31 October 2007)

\begin{abstract}
Acalculous biliary pain occurs in patients with no gallstones, but is similar to that experienced by patients with gallstones. Surgical removal of the gallbladder (GB) in these patients is only successful in providing relief of symptoms to about half of those operated on, so a reliable pain-prediction model is needed. In this paper, a mechanical model is developed for the human biliary system during the emptying phase, based on a clinical test in which GB volume changes are measured in response to a standard stimulus and a recorded pain profile. The model can describe the bile emptying behaviour, the flow resistance in the biliary ducts, the peak total stress, including the passive and active stresses experienced by the GB during emptying. This model is used to explore the potential link between GB pain and mechanical factors. It is found that the peak total normal stress may be used as an effective pain indicator for GB pain. When this model is applied to clinical data of volume changes due to Cholecystokinin stimulation and pain from 37 patients, it shows a promising success rate of $88.2 \%$ in positive pain prediction.
\end{abstract}

Keywords: Gallbladder; Total stress; Gallbladder pain; Gallstone; Flow resistance; Emptying

\section{Introduction}

Human gallbladder (GB) pain is typically described as pain in the right upper part of the abdomen lasting for $30 \mathrm{~min}$ or more and provoked by a fatty meal, but not all patients experience these classical symptoms. Gallstones are the common cause, but only a small minority of the $10 \%$ of the population with stones experience pain. GB pain, also known as acalculous biliary or functional biliary pain, is defined as a steady pain located in the epigastrium and right upper quadrant in the absence of gallstones or when no other structural abnormalities exist in the biliary tract [1]. This pain may occur up to $7.6 \%$ in men and $20.7 \%$ in women, and has received great interest in recent years [2,3]. Patients with GB pain often pose diagnostic difficulties and undergo repeated ultrasound scans and oral cholecystograms. Sonography (oral cholecystography) combined with scintigraphy is commonly used to diagnose GB pain. Reproduction of pain within 5-10 min of an injection of cholecystokinin (CCK) is also used to select a group of patients who may benefit from cholecystectomy [4].

\footnotetext{
*Corresponding author. Email: x.y.luo@maths.gla.ac.uk
} 
However, surgery is often conducted without any guarantee of relieving the symptoms. Previous attempts to provide an accurate predictor for relief of GB symptoms have not been successful with only about $50 \%$ of patients obtaining symptomatic relief following surgery [5]. Moreover, some patients without stones appear to have typical GB pain, but only half of them gain relief of their pain if the GB is removed. It is therefore important to have a way of determining whether the pain is actually arising in the GB, because similar symptoms can be produced by adjacent organs, such as the stomach, duodenum and pancreas, even without obvious disease.

Impaired motor function of GB and sphincter of Oddi has long been suspected to be a major factor contributing to GB pain. The presumed mechanism for the pain is obstruction leading to distension and inflammation. The obstruction might result from a lack of co-ordination between the GB and either the cystic duct or the sphincter of Oddi due to increased flow resistance or tone [2]. In other words, pain may be produced by contraction against resistance or stretch of the GB wall. When the GB is inflamed, artificial distension produces GB pain [6].

The pain provocation test has been used as a diagnostic tool to select patients with impaired GB motor function who may benefit from the cholecystectomy. In the test CCK is injected intravenously to stimulate the GB to contract and to induce the biliary pain. It is clinically accepted that when a GB ejection fraction (percentage of the volume displaced during emptying) is less than $35 \%$ [7] or $40 \%$ [8], then the GB motor function is considered to be impaired; otherwise, it is considered normal. It has been found that the GB pain of some patients has been alleviated after their GBs are removed [7,8]. However, conflicting reports also exist $[3,5,9]$. These facts suggest that impaired GB motor function is not the only factor responsible for the pain.

As a type of visceral pain, GB pain arises from the GB and biliary tract with obstruction of the cystic or common bile ducts, which elevates pressure within the biliary system. Some researchers believe that the pain is directly related to intraluminal pressure of the biliary tract [10]. Gaensler (1951) examined the pain threshold of common bile duct for 40 patients before and after GB removal. It was found that the pain threshold varied from 14.7 to $59 \mathrm{mmHg}$ [11]. Csendes et al. (1979) illustrated that the pain threshold is in the range 15$60 \mathrm{mmHg}$ [12]. The great variation in the pressure range in these studies suggests that the sensor of the pain in the biliary system may be better associated with other mechanical factors associated with the intraluminal pressure, but not directly to the pressure alone. Similar observations were made for pain in the oesophagus, duodenum, gastric antrum and rectum, which seems to respond to mechanoreceptors in the gastrointestinal tract wall [13]. These mechanoreceptors are found to depend on the luminal circumferential wall strain rather than pressure, tension and volume [13-17].

In this paper, we study GB pain from the mechanical point of view, i.e. the human biliary system is considered as a pressure-flow dynamic system with a flexible wall. By estimating and comparing different mechanical factors from a group of patients, we were able to identify that the peak normal stress is the single most significant mechanical factor related to the pain felt by these patients. When this is used for pain prediction, a promising $88.2 \%$ positive correlation is achieved with the clinical observations of pain for 37 patients at the Academic Surgical Unit of the Royal Hallamshire Hospital at Sheffield, UK. We emphases that this new pain predictor can be derived from non-invasive measurements of geometry changes during the emptying, thus it may feasibly serve as an aid for real-time clinical diagnosis. 


\section{Model and method}

\subsection{Acquisition of clinical data during emptying}

A CCK provocation test was carried on patients who had experienced repeated attacks of biliary-type pain in the absence of gallstones or any obvious causative findings [18]. After an overnight fast, they were given an intravenous infusion of saline (control) followed by an intravenous infusion of CCK $(0.05 \mu \mathrm{g} / \mathrm{kg}$ body weight $)$. Ultrasonography of the GB was used to monitor changes in shape, initial volume, emptying and wall thickness at 15 min intervals for $60 \mathrm{~min}$. Note that pressure is not recorded in the experiments, which would require invasive techniques. The values of pressure for different subjects are predicted using the mechanical model (below) based on the volume and shape changes measured. The patients were unaware of which substance was being given and the test was only considered positive when the patients' usual "gallbladder" pain was reproduced following CCK infusion.

Figure 1 illustrates schematically the pressure and volume variation with time during CCK provocation test. At point 1, the sphincter of Oddi is closed (see figure 2), the GB is in a fasting state, and its volume, pressure and stresses all reach their minimum levels. Between 1 and 2, a small but positive pressure difference between the liver and the GB exists, which allows the hepatic bile to be secreted slowly into the GB. During this refilling, although, the GB volume is increasing, the pressure in GB is more or less constant as the muscle relaxes. This is because the production of hepatic bile is low pressure (typically $10 \mathrm{mmHg}$ or less), continuous and easily halted by any rise in pressure in the GB or common bile duct [19]. At point 2, CCK is infused, which causes the GB to contract. The pressure in the GB rises rapidly up to point 3 in 3-5 min, and exceeds the pressure in the common bile duct. During

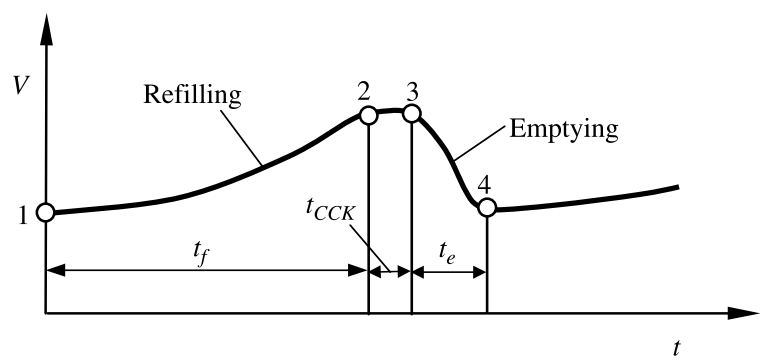

(a)

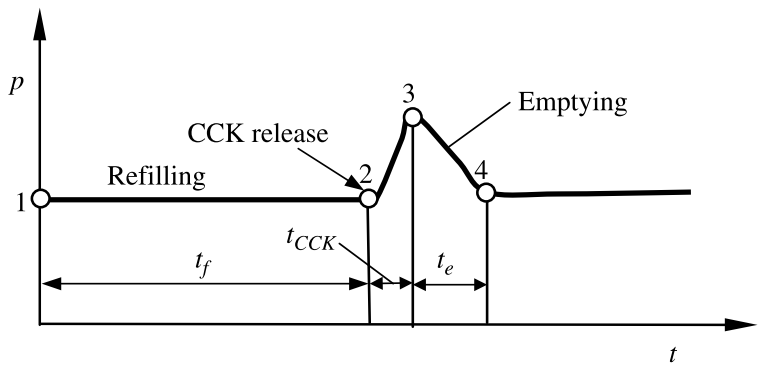

(b)

Figure 1. Diagrammatic representation of GB refilling and emptying. Refilling starts at point 1 and stops at point 2 . Emptying begins at point 2 and lasts until point 4 , when the next refilling starts. Note $t_{\mathrm{f}}$ is the refilling time $t_{\mathrm{e}}$ is the emptying time, and $t_{\mathrm{f}} \approx 6 t_{\mathrm{e}}$. 


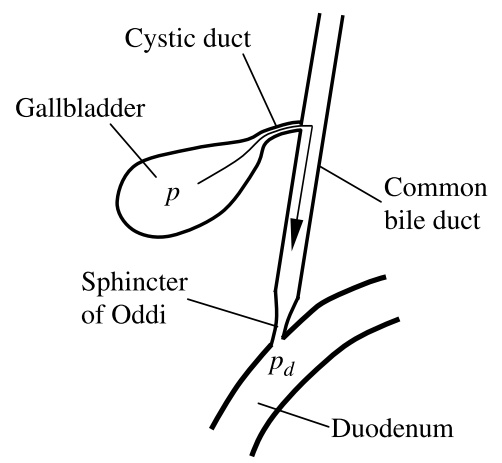

Figure 2. Bile flows into the duodenum from the GB through the cystic and common bile ducts due to the pressure difference $p-p_{\mathrm{d}}$.

this time, the sphincter of Oddi relaxes which lowers the pressure in the common bile duct further. The relative pressure in the GB is now much higher than the common bile duct, and the emptying phase takes place. For most of the subjects, this lasts for about half an hour. The time scale for refilling is usually the time lapse between two meals and is often more than six times longer than emptying.

\subsection{Mechanical modelling}

2.2.1 Predicting the pressure in gallbladder. GB emptying is caused by passive and active contractions due to the relaxation of stretch and CCK stimulation. The flow configuration in a biliary system is indicated in figure 2 . During emptying, the bile flow rate out of the GB, $Q_{\mathrm{GB}}$ $(=-\mathrm{d} V / \mathrm{d} t)$, is equal to the flow rate into the duct, $Q_{\text {duct }}$, i.e.

$$
-\frac{\mathrm{d} V}{\mathrm{~d} t}=\frac{p-p_{\mathrm{d}}}{R},
$$

where $V$ is the GB volume, $p$ is the GB pressure, $R$ is the flow resistance, and $p_{\mathrm{d}}$, the pressure in duodenum, is taken to be about $6 \mathrm{mmHg}$ [20]. Assuming that the GB volume change rate, $\mathrm{d} V / \mathrm{d} t$, is related to the pressure drop rate $\mathrm{d} p / \mathrm{d} t[21]$,

$$
\frac{\mathrm{d} V}{\mathrm{~d} t}=C \frac{\mathrm{d} p}{\mathrm{~d} t},
$$

where $C$ is the constant compliance of the GB, we have

$$
C \frac{\mathrm{d} p}{\mathrm{~d} t}+\frac{p-p_{\mathrm{d}}}{R}=0 .
$$

This is the same as the Windkessel model for the cardio-vascular system [22]. The general solution of this linear ordinary differential equation is

$$
p=p_{\mathrm{d}}-\left(p_{\mathrm{d}}-p_{\mathrm{e}}\right) \exp \left(\frac{t_{\mathrm{e}}-t}{R C}\right),
$$

where $p_{\mathrm{e}}$ indicates the pressure when the GB has completely emptied, which is chosen to be $p_{\mathrm{e}}=11 \mathrm{mmHg}$ [19], and $t_{\mathrm{e}}$ is the time taken for complete emptying. Complete emptying here 
means that the GB volume $V_{\mathrm{e}}$, at the end of emptying is $V_{\mathrm{e}}=0.3 V_{0}$, where $V_{0}$ is the volume as the emptying begins. Here, we chose $V_{\mathrm{e}}=0.3 V_{0}$ since it was found that in normal subjects a $30 \mathrm{~min}$ infusion of CCK-8 at rate of $60 \mathrm{ng} / \mathrm{kg}$ per hour causes a mean reduction in GB volume of $73 \%$ [20]. If a GB is impaired, then the time taken for complete emptying would be much longer than the normal emptying time of about $30 \mathrm{~min}$, i.e. its emptying will be incomplete when refilling starts.

In general, the GB compliance, $C$, differs from one patient to another, but, as a first approximation, we take the average value measured by Middelfart et al. for human GB, $C=2.731 \mathrm{ml} / \mathrm{mmHg}[23]$.

2.2.2 Gallbladder volume change and ejection fraction. From (2)-(4), we can also solve for GB volume,

$$
V=C\left(p_{\mathrm{e}}-p_{\mathrm{d}}\right) \exp \left(\frac{t_{\mathrm{e}}-t}{R C}\right)+B,
$$

where $B$ is a constant, which is determined using the clinical measurements of GB volume at $\left(0, V_{0}\right)(t, V)$ and $\left(t_{\mathrm{e}}, V_{\mathrm{e}}\right)$ :

$$
B=V_{\mathrm{e}}-C\left(p_{\mathrm{e}}-p_{\mathrm{d}}\right),
$$

Substituting (6) into (5) we have successively:

$$
R=\left(\frac{t}{C}\right) / \ln \left\{\frac{V_{0}-B}{V-B}\right\},
$$

and

$$
t_{\mathrm{e}}=\frac{t \ln \left[\left(V_{0}-B\right) /\left(V_{\mathrm{e}}-B\right)\right]}{\ln \left[\left(V_{0}-B\right) /(V-B)\right]} .
$$

These measurements also allow us to calculate the GB ejection fraction (EF) at 30 min after emptying as

$$
\mathrm{EF}=\frac{V_{0}-V_{30}}{V} \times 100 \% .
$$

Note for subjects $33-37$ (in table 1), the emptying is so fast that it stops before $30 \mathrm{~min}$. For these cases, EF is not estimated from (9), but is simply set to be $100 \%$.

2.2.3 Estimating the passive peak stresses. In order to estimate the peak stresses in GB muscle during emptying, we assume that the GB is an ellipsoid of homogeneous isotropic linear elastic material, with a thin uniform wall thickness, $h_{\mathrm{GB}}$. The ellipsoid has a major axis $D_{1}$, and two minor axes, $D_{2}$ and $D_{3}\left(D_{1} \geq D_{2} \geq D_{3}\right)$. Using Cartesian coordinates as shown in figure 3 , the mid-plane surface is described by

$$
\left\{\begin{array}{l}
x=0.5 D_{1} \sin \theta \cos \varphi \\
y=0.5 D_{2} \sin \theta \sin \varphi \\
z=0.5 D_{3} \cos \theta
\end{array}\right.
$$




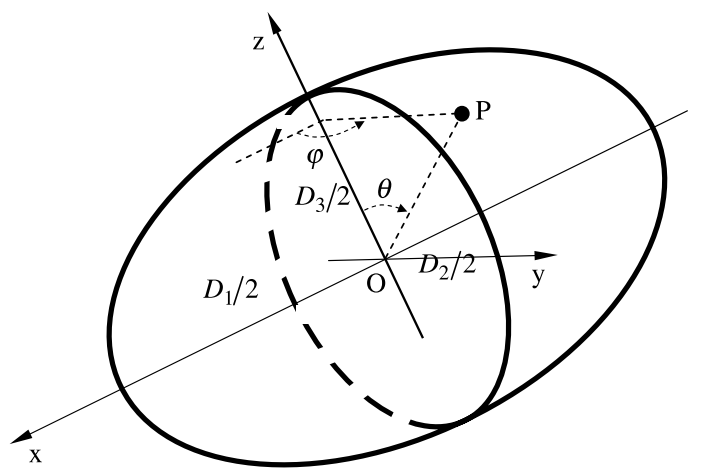

Figure 3. GB shape is assumed to be ellipsoidal during emptying, the major axis length is $D_{1}$, the minor axis length are $D_{2}$, and $D_{3}\left(D_{1}>D_{2} \geq D_{3}\right)$. The GB is subjected to a uniform internal pressure. The stress due to this pressure at a point $\mathrm{P}$ has three components: $\sigma_{\theta}$ (meridian), $\sigma_{\varphi}$ (latitude), and $\tau_{\theta \varphi}$ (in surface).

where $\theta$ and $\varphi$ are the two independent angular variables for a point position on the surface, and $\theta$ is in the meridian plane and measured from the positive $z$ axis, $\theta \in[0, \pi]$; whereas, $\varphi$ is in the latitude plane, which is perpendicular to $z$ axis, and measured from the first quadrant of $x-z$ plane, and $\varphi \in[0,2 \pi]$. The stresses in the ellipsoid surface under a uniform inner fluid pressure load $p$ are given by [24],

$$
\left\{\begin{array}{l}
\sigma_{\theta}=\frac{p D_{3} k_{1} k_{2}}{4 h_{\mathrm{GB}}}\left[1-\frac{k_{1}^{2}-k_{2}^{2}}{k_{1}^{2} k_{2}^{2}} \cos 2 \varphi\right] F \\
\sigma_{\varphi}=\frac{p D_{3}}{4 k_{1} k_{2} h_{\mathrm{GB}}}\left[k_{1}^{2} k_{2}^{2}+\left(k_{1}^{2}+k_{2}^{2}-2 k_{1}^{2} k_{2}^{2}\right) \sin ^{2} \theta+\left(k_{1}^{2}-k_{2}^{2}\right) \cos ^{2} \theta \cos 2 \varphi\right] \frac{1}{F}, \\
\tau_{\theta \varphi}=\frac{p D_{3}}{4 k_{1} k_{2} h_{\mathrm{GB}}}\left(k_{1}^{2}-k_{2}^{2}\right) \cos \theta \sin 2 \varphi
\end{array}\right.
$$

where $k_{1}=D_{1} / D_{3}, k_{2}=D_{2} / D_{3}$ and $F$ is

$$
F=\frac{\sqrt{k_{1}^{2} \cos ^{2} \theta \cos ^{2} \varphi+k_{2}^{2} \cos ^{2} \theta \sin ^{2} \varphi+\sin ^{2} \theta}}{\sqrt{k_{1}^{2} \sin ^{2} \varphi+k_{2}^{2} \cos ^{2} \varphi}} .
$$

The mean wall thickness of healthy human $\mathrm{GB}, h_{\mathrm{GB}}$, is taken to be $2.5 \mathrm{~mm}$ [25]. The maximum normal stress is then

$$
\sigma_{\max }=\max \left[\sigma_{\theta}, \sigma_{\varphi}\right]
$$

and the peak shear stress is

$$
\tau_{\max }=\max \left[\tau_{\theta \varphi}\right]
$$

To estimate the values of $\sigma_{\max }$ and $\tau_{\max }$, the GB domain was divided into $200 \times 100$ elements, and the values of the stresses were calculated from (11) at each node of the elements.

2.2.4 Contribution of the active normal stress. During emptying, the GB contracts due to $\mathrm{CCK}$, which induces the active stress. In this study, for simplicity, we will assume that all 


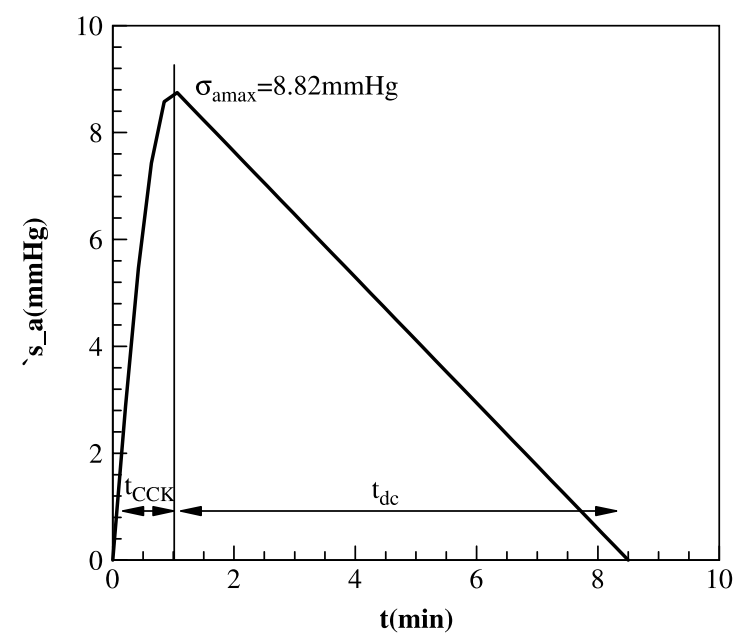

Figure 4. GB response curve to CCK [26]. $t_{\mathrm{CCK}}$ is the CCK response time, and $t_{\mathrm{dc}}$ is the CCK decay time, $\sigma_{\mathrm{a} \max }$ is the peak active stress.

patients experience the same level of CCK stimulation, which induces the same peak active normal stress. Thus, we use a uniform response curve to CCK, estimated from experiments [26], as shown in figure 4. This curve can be interpolated using

$$
\sigma_{\mathrm{a}}=\left\{\begin{array}{cc}
\sigma_{\mathrm{a} \max } \sin \left(\frac{\pi t}{2 t_{\mathrm{CCK}}}\right) & t \leq t_{\mathrm{CCK}} \\
\sigma_{\mathrm{a} \max }\left(1-\frac{t-t_{\mathrm{CCK}}}{t_{\mathrm{dc}}}\right) & t>t_{\mathrm{CCK}}
\end{array}\right.
$$

where $\sigma_{\mathrm{a} \text { max }}$ is the maximum active stress taken to be $8.82 \mathrm{mmHg}, t_{\mathrm{CCK}}$ and $t_{\mathrm{dc}}$ are chosen to be $t_{\mathrm{CCK}}=1 \mathrm{~min}$ and $t_{\mathrm{dc}}=7.5 \mathrm{~min}$ [27]. There are no reports on active shear stress due to CCK. Finally, the total maximum normal stress in the GB wall during the emptying is thus

$$
\sigma_{\mathrm{t} \max }=\sigma_{\mathrm{a} \max }+\sigma_{\max } .
$$

It is emphasized again that the contribution of the active stress in this model is assumed to be uniform for all patients. As active stress is highly likely to be patient and deformation dependent, better and more realistic modelling of this contribution is required in future.

\section{Results}

The clinical data for 37 patients during emptying were provided by the Royal Hallamshire Hospital, Sheffield, UK. Based on these data, we have calculated various factors, summarized in table 1.

All the initial GB volumes are in the range of $15-35 \mathrm{ml}$, except for those of subjects 19 and 37 , which have an initial volume of 60 and $10 \mathrm{ml}$, respectively. The average initial GB volume is $25.3 \mathrm{ml}$. The GB volume change versus time is plotted in figure 5, for three typical subjects: 1,18 and 37, which indicates, respectively, poor, fair and super-emptying behaviour. 
Table 1. Major parameters of GB during emptying.

\begin{tabular}{|c|c|c|c|c|c|c|c|c|c|}
\hline GB & $V_{0}(\mathrm{ml})$ & $t(\min )$ & $\mathrm{EF}(\%)$ & $R$ & $D_{1}(\mathrm{~mm}), k_{1}, k_{2}$ & $p_{\max }(\mathrm{mmHg})$ & $\sigma_{\mathrm{t} \max }(\mathrm{mmHg})$ & $\tau_{\max }(\mathrm{mmHg})$ & Clinical observation \\
\hline 1 & 16.6 & 15 & 4.2 & 392.6 & $54.1,2.31,1.07$ & 15.2 & 92.9 & 52.9 & No pain \\
\hline 2 & 33.0 & 20 & 5.5 & 217.6 & $59.7,2.01,1.19$ & 19.4 & 142.7 & 54.7 & No pain \\
\hline 3 & 25.5 & 22 & 9.7 & 134.1 & $72.2,2.81,1.02$ & 17.5 & 130.7 & 94.4 & No pain \\
\hline 4 & 36.8 & 27 & 12.2 & 90.7 & $64.9,2.01,1.04$ & 20.4 & 141.6 & 81.8 & No pain \\
\hline 5 & 13.3 & 20 & 13.8 & 131.6 & $74.1,4.49,1.26$ & 14.4 & 367.5 & 68.1 & Pain \\
\hline 6 & 21.1 & 15 & 14.8 & 94.4 & $68.8,3.31,1.35$ & 16.4 & 290.1 & 60.8 & Pain \\
\hline 7 & 23.0 & 10 & 16.6 & 80.0 & $57.3,2.34,1.28$ & 18.9 & 150.4 & 51.4 & No pain \\
\hline 8 & 33.5 & 20 & 20.5 & 53.8 & $66.7,2.52,1.37$ & 19.6 & 210.0 & 59.0 & Pain \\
\hline 9 & 23.1 & 10 & 21.3 & 60.1 & $61.1,2.97,1.58$ & 17.1 & 300.8 & 39.6 & Pain \\
\hline 10 & 21.0 & 15 & 23.6 & 64.6 & $73.0,3.65,1.10$ & 15.3 & 133.7 & 80.6 & No pain \\
\hline 11 & 36.3 & 21 & 24.5 & 42.5 & $81.7,3.35,1.43$ & 20.3 & 514.3 & 83.1 & No pain \\
\hline 12 & 22.0 & 11 & 26.2 & 49.7 & $71.5,3.26,1.22$ & 16.6 & 209.1 & 72.8 & No pain \\
\hline 13 & 20.1 & 15 & 28.0 & 48.5 & $63.2,3.07,1.43$ & 16.2 & 271.4 & 48.8 & Pain \\
\hline 14 & 21.5 & 28 & 30.0 & 43.2 & $63.5,3.41,1.87$ & 16.5 & 770.1 & 34.2 & Pain \\
\hline 15 & 25.5 & 15 & 32.1 & 34.3 & $72.0,2.82,1.18$ & 18.4 & 217.3 & 68.8 & Pain \\
\hline 16 & 12.6 & 10 & 32.3 & 55.0 & $50.6,2.42,1.09$ & 14.2 & 85.7 & 45.8 & No pain \\
\hline 17 & 21.7 & 10 & 37.8 & 32.9 & $55.9,2.06,1.00$ & 16.6 & 98.8 & 61.8 & Pain \\
\hline 18 & 18.0 & 10 & 39.5 & 35.7 & $57.6,2.02,1.03$ & 15.4 & 95.1 & 62.8 & Pain \\
\hline 19 & 59.9 & 15 & 40.4 & 19.3 & $92.3,2.66,1.03$ & 26.3 & 246.6 & 175.2 & Pain \\
\hline 20 & 24.1 & 21 & 47.0 & 23.6 & $58.0,2.12,1.07$ & 17.2 & 111.0 & 61.2 & Pain \\
\hline 21 & 15.6 & 15 & 51.2 & 27.9 & $74.5,2.64,1.07$ & 15.0 & 82.9 & 20.1 & No pain \\
\hline 22 & 33.1 & 15 & 60.5 & 14 & $41.0,1.69,1.24$ & 19.5 & 156.6 & 99.5 & Pain \\
\hline 23 & 33.9 & 10 & 61.5 & 13.5 & $77.5,3.18,1.40$ & 19.7 & 403.6 & 76.6 & Pain \\
\hline 24 & 28.3 & 10 & 61.7 & 59.0 & $63.0,2.42,1.27$ & 18.3 & 138.0 & 57.6 & No pain \\
\hline 25 & 42.6 & 10 & 63.0 & 11.4 & $75.4,2.62,1.30$ & 22.0 & 249.1 & 83.5 & Pain \\
\hline 26 & 30.1 & 15 & 63.8 & 13.7 & $75.8,3.08,1.25$ & 18.7 & 246.8 & 82.5 & Pain \\
\hline 27 & 23.0 & 15 & 70.2 & 14.1 & $64.8,2.61,1.10$ & 16.9 & 246.6 & 71.6 & Pain \\
\hline 28 & 26.2 & 15 & 71.1 & 12.6 & $68.0,2.61,1.07$ & 17.7 & 132.8 & 80.5 & No pain \\
\hline 29 & 24.1 & 15 & 75.5 & 12.1 & $56.7,2.02,1.03$ & 17.2 & 105.9 & 61.3 & No pain \\
\hline 30 & 26.7 & 11 & 79.3 & 10.4 & $68.6,2.85,1.28$ & 17.8 & 210.7 & 66.6 & Pain \\
\hline 31 & 21.6 & 9 & 89.8 & 6.9 & $74.2,3.84,1.49$ & 16.5 & 590.1 & 60.9 & Pain \\
\hline 32 & 18.2 & 15 & 97.1 & 5.0 & $55.4,2.30,1.08$ & 15.7 & 99.0 & 54.6 & No pain \\
\hline 33 & 25.7 & 7 & 100.0 & 1.7 & $63.0,2.24,1.15$ & 17.6 & 132.1 & 64.9 & No pain \\
\hline 34 & 19.0 & 20 & 100.0 & 9.4 & $67.0,3.66,1.62$ & 15.9 & 595.5 & 46.2 & Pain \\
\hline 35 & 10.0 & 11 & 100.0 & 6.5 & $45.8,2.65,1.39$ & 13.6 & 119.1 & 28.2 & Pain \\
\hline 36 & 23.7 & 15 & 100.0 & 6.7 & $76.1,3.34,1.14$ & 17.1 & 173.1 & 87.6 & No pain \\
\hline 37 & 26.2 & 12 & 100.0 & 11.1 & $53.8,1.78,1.02$ & 17.7 & 104.2 & 54.8 & No pain \\
\hline
\end{tabular}

NB. For subjects $33-37$, emptying is finished before $30 \mathrm{~min}$. EF for these subjects is taken to be $100 \%$. 


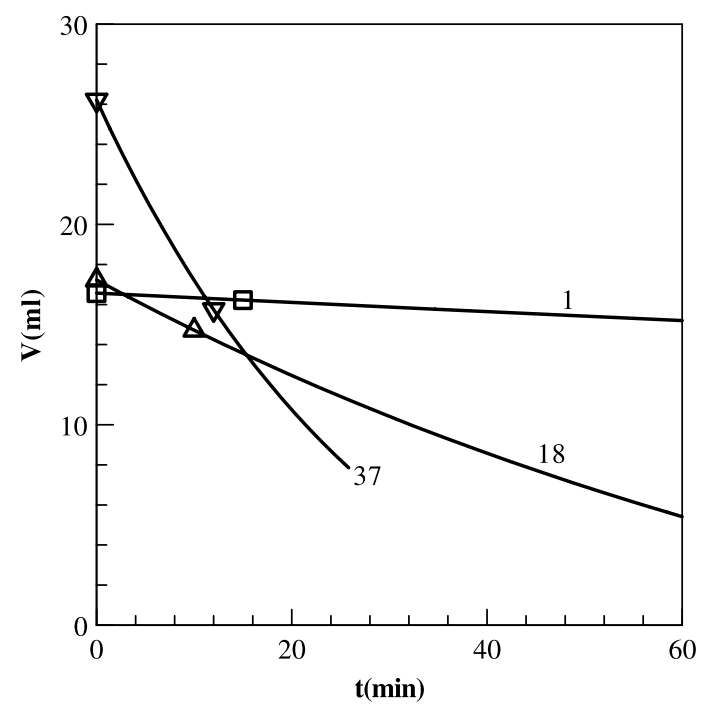

Figure 5. GB volume variation with time during emptying for 3 typical subjects. The symbols are the experimental data and the solid curves are from (5).

The flow resistance varies from 1.7 to $392.6 \mathrm{mmHg} / \mathrm{ml}$ per minute, showing a significant variation across the subjects. The subjects with good emptying (large EF) have low flow resistance and those with poor emptying (small EF) usually present high resistance. In general, the resistance is in the range of $20-70 \mathrm{mmHg} / \mathrm{ml}$ per minute. The average resistance is $53.4 \mathrm{mmHg} / \mathrm{ml}$ per minute, however the resistances of subjects $1-3$, and 5 are all higher than $130 \mathrm{mmHg}$. The resistance of the cystic duct of the prairie dog is found to increase from 50 to $120 \mathrm{mmHg} / \mathrm{ml}$ per minute when its GB changed from healthy status to that with gallstones after feeding with a cholesterol diet [28]. Thus if we can extend the experimental finding for prairie dogs to human, then it is likely that these with higher resistances indicate the unhealthy states.

The maximum values of the pressure, $p_{\max }$, for all subjects are given in table 1 and the pressure variation with time is illustrated in figure 6 for subjects 1,18 and 37. It can be seen that the peak pressure of most of the GBs, except GB 19, is in the range of $15-20 \mathrm{mmHg}$. This agrees well with physiological values [20]. The GB pressure of subjects $1-14$, which have poor emptying, decreases more slowly with time. In general, the flatness of the pressure curves seems to be associated with poor emptying. In other words, a GB with poor-emptying is subject to a higher pressure for a longer period of time.

The GB shapes in the subject group in table 1 can be characterized by two main geometric types: those (type 1) for which the ellipsoid is elongated with $k_{2}>1$; and those (type 2 ) for which the ellipsoid is a spheroid and $k_{2} \approx 1$. The peak normal stress level of first type is higher than that of second type; see figure 7 for subjects 12 (type $1, k_{2}=1.22$ ) and 17 (type 2, $k_{2}=1.0$ ). The shear stress patterns for these two subjects are similar, with the maximum/minimum values occurring at the same orientation: $\theta=\varphi=45^{\circ}$, but are very different to the normal stresses. This is because the maximum value of the normal stress is much more sensitive to the geometric changes, therefore, its location and value can differ significantly for different geometric types.

When these factors are compared with the pain information from clinical observations in table 1, it shows that the direct correlations with pain of the flow resistance, shear stress, and 


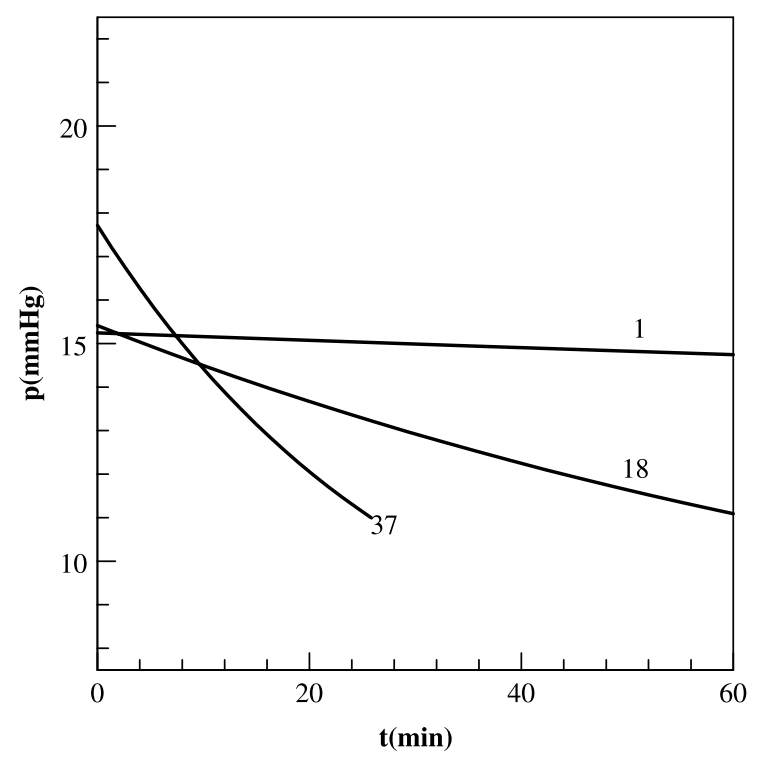

Figure 6. The pressure variation with time during emptying for subjects 1, 18 and 37, respectively.

$\mathrm{EF}$ are all rather poor. The maximum pressure, $p_{\max }$, seems to be weakly correlated with pain. The most remarkable correlation, however, is found to be with the maximum normal stress $\sigma_{\mathrm{t} \text { max }}$.

In the following, we consider three pain predictors based on (1) ejection fraction: $\mathrm{EF}<35 \%$, which is commonly used in clinics, (2) pressure: $p>15.4 \mathrm{mmHg}(15.4 \mathrm{mmHg}$ is estimated when patients' average $\mathrm{EF}$ is $35 \%$ ) and (3) maximum normal stress: $\sigma_{\mathrm{t} \max }>\sigma^{*}$, where $\sigma^{*}=200 \mathrm{mmHg}$ is from an average value calculated from pressure measurement by Gaenseler [11]. The results of the predictions are listed in tables 2-4.

From table 3, it is clear that all predictions using $\sigma_{\mathrm{t} \max }$ are correct except for GBs 11, 12, $17,18,20,22$ and 35 , thus out of 37 cases, 30 agree with the clinical observations. For comparison, if we use $\mathrm{EF}<35 \%$ as the pain threshold, the results are far less positive, with less than half agreeing with clinical data. The correlations of the shear stress and resistance are also poor to pain. The results from using $p>15.4 \mathrm{mmHg}$ is better than using EF, but not as good as using $\sigma_{\mathrm{t} \text { max }}$.

In order to see how reliable these predictions are, below we analyse these from a more rigorous statistical standpoint, making use of the logistic transformation (see appendix A).

Table 5 is the $2 \times 2$ contingency table for the three pain related indices, EF, $p_{\max }$ and $\sigma_{\mathrm{t} \max }$, where the counts of the success and failure based on clinical observations are listed. The corresponding success and failure rates are also listed in brackets. It can be seen that the success rates of positive (pain) and negative (no pain) predictions using EF is all less than 0.5 . Therefore, this index has no prediction power and should be rejected.

The success rates of the positive and negative predictions using $p_{\max }$ are somewhere between 0.5 and 0.7 . Interestingly, the rate of its negative prediction is better than the positive prediction. However, for $\sigma_{\mathrm{t} \text { max }}$ both (positive and negative) the success rates are over 0.75 , with the positive (pain) prediction as high as 0.882 .

The $95 \%$ confidence intervals for the success rate of pain and no pain predictions are shown in table 6 . The difference between the success rates of positive and negative 

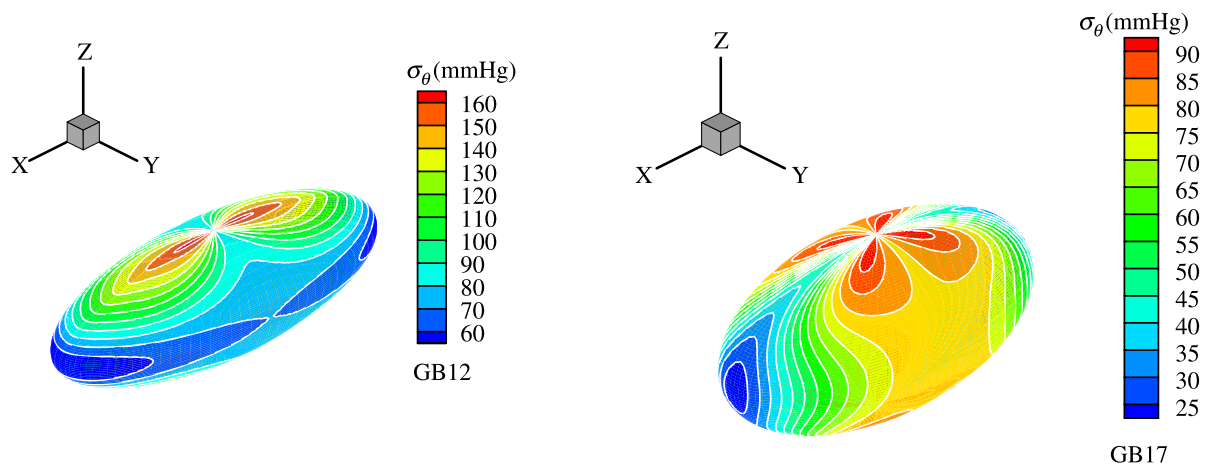<smiles>[X][C]1C([X])=C1[Y]</smiles>
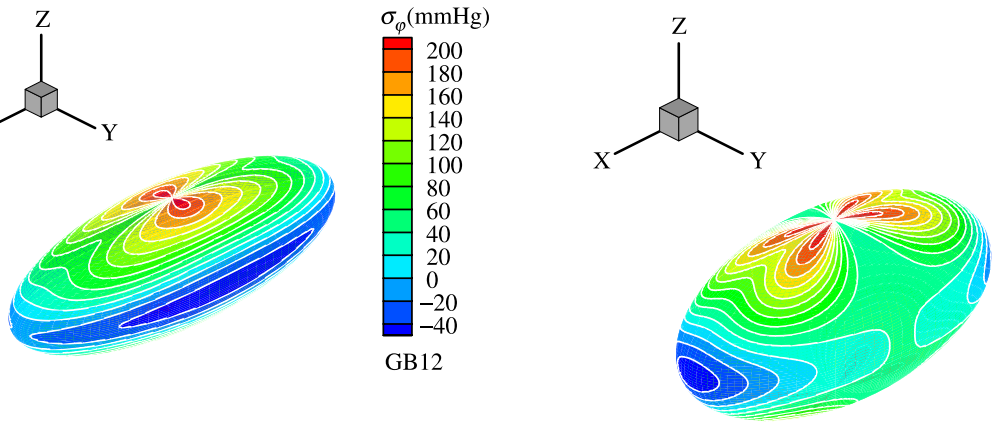

$\sigma_{\varphi}(\mathrm{mmHg})$
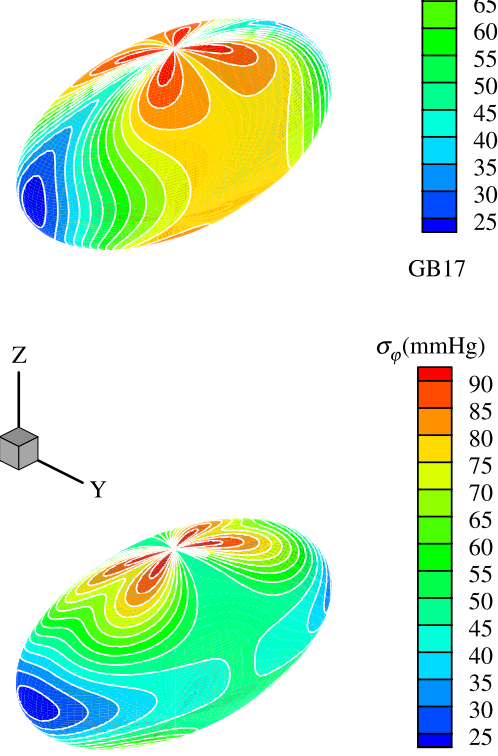

GB17
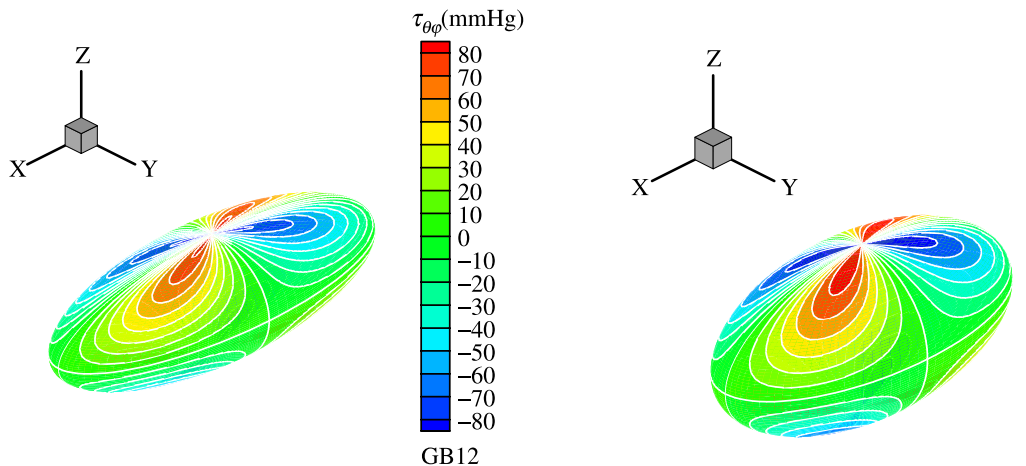

$\tau_{\theta \varphi}(\mathrm{mmHg})$

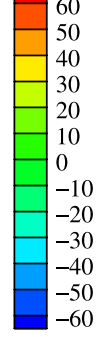

GB17

$$
k_{2}<1
$$

$$
k_{2}=1
$$

Figure 7. The stress contours on the GB wall at the start of emptying for subjects 12 (left) and 17 (right). The top frame is the principal stress $\sigma_{\theta}$, the middle frame is the principal stress $\sigma_{\varphi}$, and the bottom one is the shear stress $\tau_{\theta \varphi}$.

predictions can be seen by using the ratio of odds from the two rows in the $2 \times 2$ contingency table (see table 5). The inference for the odds ratio of positive (pain) and negative (no pain) predictions is summarized in table 7 for both $p_{\max }$ and $\sigma_{\mathrm{t} \max }$. The $95 \%$ confidence interval for odds ratio of success rate of positive (pain) and negative (no pain) prediction with $p_{\max }$ is $(0.60,0.769)$ i.e. using this index, the success rate of pain prediction is at least $23.1 \%$ less than no pain prediction. Whilst with $\sigma_{\mathrm{t} \text { max }}$ this is $(1.373,1.605)$, thus the 
Table 2. GB pain prediction using bile EF.

\begin{tabular}{|c|c|c|c|c|}
\hline GB & $\mathrm{EF}(\%)$ & Pain prediction & Clinical observation & Agreement \\
\hline 1 & 4.2 & Positive & Negative & No \\
\hline 2 & 5.5 & Positive & Negative & No \\
\hline 3 & 9.7 & Positive & Negative & No \\
\hline 4 & 12.2 & Positive & Negative & No \\
\hline 5 & 13.8 & Positive & Positive & Yes \\
\hline 6 & 14.8 & Positive & Positive & Yes \\
\hline 7 & 16.6 & Positive & Negative & No \\
\hline 8 & 20.5 & Positive & Positive & Yes \\
\hline 9 & 21.3 & Positive & Positive & Yes \\
\hline 10 & 23.6 & Positive & Negative & No \\
\hline 11 & 24.5 & Positive & Negative & No \\
\hline 12 & 26.2 & Positive & Negative & No \\
\hline 13 & 28.0 & Positive & Positive & Yes \\
\hline 14 & 30.0 & Positive & Positive & Yes \\
\hline 15 & 32.1 & Positive & Positive & Yes \\
\hline 16 & 32.3 & Positive & Negative & No \\
\hline 17 & 37.8 & Negative & Positive & No \\
\hline 18 & 39.5 & Negative & Positive & No \\
\hline 19 & 40.4 & Negative & Positive & No \\
\hline 20 & 47.0 & Negative & Positive & No \\
\hline 21 & 51.2 & Negative & Negative & Yes \\
\hline 22 & 60.5 & Negative & Positive & No \\
\hline 23 & 61.5 & Negative & Positive & No \\
\hline 24 & 61.7 & Negative & Negative & Yes \\
\hline 25 & 63.0 & Negative & Positive & No \\
\hline 26 & 63.8 & Negative & Positive & No \\
\hline 27 & 70.2 & Negative & Positive & No \\
\hline 28 & 71.1 & Negative & Negative & Yes \\
\hline 29 & 75.5 & Negative & Negative & Yes \\
\hline 30 & 79.3 & Negative & Positive & No \\
\hline 31 & 89.8 & Negative & Positive & No \\
\hline 32 & 97.1 & Negative & Negative & Yes \\
\hline 33 & 100.0 & Negative & Negative & Yes \\
\hline 34 & 100.0 & Negative & Positive & No \\
\hline 35 & 100.0 & Negative & Positive & No \\
\hline 36 & 100.0 & Negative & Negative & Yes \\
\hline 37 & 100.0 & Negative & Negative & Yes \\
\hline
\end{tabular}

success rate of pain prediction is $37.5 \%$ higher than no pain prediction. This is important as in clinical diagnosis, the significance of a reliable positive prediction is much greater than that of a negative prediction. Therefore, we believe that the peak normal stress is the better pain prediction compared with the maximum pressure (table 7).

\section{Discussions}

Our study shows that the peak normal stress is a good index to use for pain prediction. This prediction is correct for all but seven subjects (table 4) in all 37 cases studied. A reason for the seven failed cases could be that these patients have slightly lower or higher pain threshold levels than the standard value used. It is also likely to be the simplifications introduced in the model, such as a uniform GB compliance, and an elliptical GB shape, which are used in the model for every subject, whereas in reality, should all be subject-dependent. 
Table 3. GB pain prediction using the peak pressure.

\begin{tabular}{|c|c|c|c|c|}
\hline GB & $p_{\max }(\mathrm{mmHg})$ & Pain predicted & Clinical observation & Agreement \\
\hline 35 & 13.6 & Negative & Positive & No \\
\hline 16 & 14.2 & Negative & Negative & Yes \\
\hline 5 & 14.4 & Negative & Positive & No \\
\hline 21 & 15.0 & Negative & Negative & Yes \\
\hline 1 & 15.2 & Negative & Negative & Yes \\
\hline 10 & 15.3 & Negative & Negative & Yes \\
\hline 18 & 15.4 & Positive & Positive & Yes \\
\hline 32 & 15.7 & Positive & Negative & No \\
\hline 34 & 15.9 & Positive & Positive & Yes \\
\hline 13 & 16.2 & Positive & Positive & Yes \\
\hline 6 & 16.4 & Positive & Positive & Yes \\
\hline 14 & 16.5 & Positive & Positive & Yes \\
\hline 31 & 16.5 & Positive & Positive & Yes \\
\hline 12 & 16.6 & Positive & Negative & No \\
\hline 17 & 16.6 & Positive & Positive & Yes \\
\hline 27 & 16.9 & Positive & Positive & Yes \\
\hline 9 & 17.1 & Positive & Positive & Yes \\
\hline 36 & 17.1 & Positive & Negative & No \\
\hline 20 & 17.2 & Positive & Positive & Yes \\
\hline 29 & 17.2 & Positive & Negative & No \\
\hline 3 & 17.5 & Positive & Negative & No \\
\hline 33 & 17.6 & Positive & Negative & No \\
\hline 28 & 17.7 & Positive & Negative & No \\
\hline 37 & 17.7 & Positive & Negative & No \\
\hline 30 & 17.8 & Positive & Positive & Yes \\
\hline 24 & 18.3 & Positive & Negative & No \\
\hline 15 & 18.4 & Positive & Positive & Yes \\
\hline 26 & 18.7 & Positive & Positive & Yes \\
\hline 7 & 18.9 & Positive & Negative & No \\
\hline 2 & 19.4 & Positive & Negative & No \\
\hline 22 & 19.5 & Positive & Positive & Yes \\
\hline 8 & 19.6 & Positive & Positive & Yes \\
\hline 23 & 19.7 & Positive & Positive & Yes \\
\hline 11 & 20.3 & Positive & Negative & No \\
\hline 4 & 20.4 & Positive & Negative & No \\
\hline 25 & 22.0 & Positive & Positive & Yes \\
\hline 19 & 26.3 & Positive & Positive & Yes \\
\hline
\end{tabular}

It is important to realise that the peak normal stresses in GB wall not only depend on the pressure $p$, but also on its geometry, $D_{1}, D_{2}$ and $D_{3}$, and their relative ratios, see table 1 . In fact, we believe that it is through the normal stress mechanism that the effects from both the pressure and the geometry change come into play in producing pain. Additionally, it is interesting to note that a poor emptying rate (a lower ejection fraction) is not necessarily associated with the pain, subjects $1-4,7$ and 10-12 have all showed poor emptying, but do not experience any pain, both from the model prediction, or from the clinical observation. The GBs with super emptying (a larger ejection fraction value) can also demonstrate pain, for instance, subjects 31 and 34. Therefore, the ejection fraction is not considered to be a good indicator for pain prediction. This is important since impaired GB emptying is still used as the clinical criterion for cholecystectomy [1]. Our study clearly suggests that this criterion needs to be reviewed.

However, we should point out that there are limitations in our current approach. We have assumed here that the GB is an ellipsoid, which is a commonly adopted assumption in clinical 
Table 4. Pain prediction using the peak normal stress.

\begin{tabular}{|c|c|c|c|c|}
\hline GB & $\sigma_{\mathrm{t} \max }(\mathrm{mmHg})$ & Pain predicted & Clinical observation & Agreement \\
\hline 21 & 82.9 & Negative & Negative & Yes \\
\hline 16 & 85.7 & Negative & Negative & Yes \\
\hline 1 & 92.9 & Negative & Negative & Yes \\
\hline 18 & 95.1 & Negative & Positive & No \\
\hline 17 & 98.8 & Negative & Positive & No \\
\hline 32 & 99.0 & Negative & Negative & Yes \\
\hline 37 & 104.2 & Negative & Negative & Yes \\
\hline 29 & 105.9 & Negative & Negative & Yes \\
\hline 20 & 111.0 & Negative & Positive & No \\
\hline 35 & 119.1 & Negative & Positive & No \\
\hline 3 & 130.7 & Negative & Negative & Yes \\
\hline 33 & 132.1 & Negative & Negative & Yes \\
\hline 28 & 132.8 & Negative & Negative & Yes \\
\hline 10 & 133.7 & Negative & Negative & Yes \\
\hline 24 & 138.0 & Negative & Negative & Yes \\
\hline 4 & 141.6 & Negative & Negative & Yes \\
\hline 2 & 142.7 & Negative & Negative & Yes \\
\hline 7 & 150.4 & Negative & Negative & Yes \\
\hline 22 & 156.6 & Negative & Positive & No \\
\hline 36 & 173.1 & Negative & Negative & Yes \\
\hline 12 & 209.1 & Positive & Negative & No \\
\hline 8 & 210.0 & Positive & Positive & Yes \\
\hline 30 & 210.7 & Positive & Positive & Yes \\
\hline 15 & 217.3 & Positive & Positive & Yes \\
\hline 19 & 246.6 & Positive & Positive & Yes \\
\hline 27 & 246.6 & Positive & Positive & Yes \\
\hline 26 & 246.8 & Positive & Positive & Yes \\
\hline 25 & 249.1 & Positive & Positive & Yes \\
\hline 13 & 271.4 & Positive & Positive & Yes \\
\hline 6 & 290.1 & Positive & Positive & Yes \\
\hline 9 & 300.8 & Positive & Positive & Yes \\
\hline 5 & 367.5 & Positive & Positive & Yes \\
\hline 23 & 403.6 & Positive & Positive & Yes \\
\hline 11 & 514.3 & Positive & Negative & No \\
\hline 31 & 590.1 & Positive & Positive & Yes \\
\hline 34 & 595.5 & Positive & Positive & Yes \\
\hline 14 & 770.1 & Positive & Positive & Yes \\
\hline
\end{tabular}

practice (e.g. in real-time Ultrasonography). However, this approximation can cause an error up to $10 \%$ in estimates of GB size [29]. Our model can be improved if the GB volume can be obtained more accurately, which may be possible with improved clinical instrumentation. Another limitation is that we have assumed that GB behaves as a homogenous linear isotropic elastic material. Future work is required to estimate the importance and influence

Table 5. Counts of the success rate of positive (pain) and negative (no pain) prediction by using the three predictors.

\begin{tabular}{lcccc}
\hline Predictor & Prediction & Success & Failure & Sample size \\
\hline EF & Positive (pain) & $7(0.438)$ & $9(0.562)$ & 16 \\
& Negative (no pain) & $8(0.381)$ & $13(0.619$ & 21 \\
$p_{\max }$ & Positive (pain) & $18(0.581)$ & $13(0.219)$ & 31 \\
$\sigma_{\mathrm{t} \max }$ & Negative (no pain) & $4(0.667)$ & $2(0.333)$ & 6 \\
& Positive (pain) & $15(0.882)$ & $2(0.118)$ & 17 \\
& Negative (no pain) & $15(0.75)$ & $5(0.25)$ & 20 \\
\hline
\end{tabular}


Table 6. 95\% confidence intervals of the success rate of positive (pain) and negative (no pain) prediction.

\begin{tabular}{lcc}
\hline Predictor & Success rate of positive (pain) and negative (no pain) prediction & Confidence interval \\
\hline EF & 0.438 & $(0.225,0.677)$ \\
& 0.381 & $(0.203,0.598)$ \\
$p_{\max }$ & 0.581 & $(0.405,0.739)$ \\
$\sigma_{\mathrm{t} \max }$ & 0.667 & $(0.268,0.916)$ \\
& 0.882 & $(0.631,0.970)$ \\
& 0.75 & $(0.522,0.892)$ \\
\hline
\end{tabular}

Table 7. Inference for the odds ratio of positive (pain) and negative (no pain) prediction.

\begin{tabular}{lccc}
\hline Predictor & Odds ratio of sample & Asymptotic standard error of sample & $\begin{array}{c}\text { 95\% confidence interval for odds } \\
\text { ratio with normal distribution }\end{array}$ \\
\hline$p_{\max }$ & -0.386 & -0.063 & $(0.60,0.769)$ \\
$\sigma_{\mathrm{t} \max }$ & 0.396 & -0.0395 & $(1.375,1.605)$ \\
\hline
\end{tabular}

of nonlinearity and anisotropy on the stress calculations. We have also assumed a uniform thickness of GB wall, which may also bring in some degree of inaccuracy in our predictions. Detailed measurement of the thickness changes, especially when GB wall is in contraction, is required before any further analysis can be carried out. In addition, although this model has included both active and passive stresses, the active stress is not obtained from the smooth muscle mechanics, rather it is taken to be the same typical form for all subjects applied uniformly over the GB wall. In practice, this also varies with individual subject. There should be a range of values for the threshold stress at which patients can feel pain, i.e. the pain sensitivity is individual. Using a standard value of $200 \mathrm{mmHg}$ here is only an approximation. Finally, the number of clinical samples that we have been able to use over the last few years is still relatively small, being 37 only. For a more reliable pain prediction, more samples should be included. Further and more extensive studies from our and other groups are clearly required. Much greater knowledge about the smooth muscle function in the GB, remodelling and growth during abnormal emptying, and the mechanical sensor related to the pain, as well as the individual pain threshold, are all required in order to understand the precise mechanism of the GB pain.

Having mentioned all these limitations, it is encouraging that a simple model based on non-invasive clinical measurement (volume changes) may be used to predict the pain with $88.2 \%$ positive success rate for the samples studied. However, although, this study suggests that a simple model can provide a good first approximation to this complicated problem, more extensive studies on a wide range of patients under more controlled conditions (on age and gender) are clearly required to confirm this.

\section{Conclusions}

In this paper, a simple GB model is developed to evaluate the correlations of the mechanical factors with GB pain, based on clinical data for 37 patients. These factors include the GB 
pressure, ejection fraction, flow resistance, shear stress, and peak shear and normal stresses. It is found that the peak normal stress is the best mechanical factor that may be used to predict the GB pain. Using this as a pain criterion, the agreement with 37 clinical observations (for positive prediction) is about $88.2 \%$. On the other hand, it is found that, a poor emptying, the maximum pressure in GB, the peak shear stress, and the flow resistance, do not correlate directly with pain. This is because the normal stress in GB wall depends not only on the GB pressure (i.e. flow resistance), but also on the GB geometry. Although this is simple model and has only been tested for 37 patients, its simplicity, and the fact that it requires the minimum clinical data, makes it a promising potential as one of the routine clinical diagnostic methods.

\section{Acknowledgements}

We would like to thank SWANN MORTON Ltd, Universities of Sheffield and Glasgow, for the financial support for this research. Helpful discussions with Dr Aitchison of the Department of Statistics, University of Glasgow are gratefully acknowledged.

\section{References}

[1] Shaffer, E., 2003, Acalculous biliary pain: new concepts for an old entity, Digestive and Liver Disease, 35(Suppl 3), S20-S25.

[2] Corazziari, E., Shaffer, E.A., Hogan, W.J., Sherman, S. and Toouli, J., 1999, Functional disorders of the biliary tract and pancreas, Gut, 45(Suppl II), II48-II54.

[3] Rastogi, A., Slivka, A., Moser, A.J. and Wald, R., 2005, Controversies concerning pathophysiology and management of acalculous biliary-type abdominal pain, Digestive Diseases and Sciences, 50(8), $1391-1401$.

[4] Williamson, R.C.N., 1988, Acalculous disease of gall bladder, Gut, 29, 860-872.

[5] Smythe, A., Majeed, A.W., Fitzhenry, M. and Johnson, A.G., 1998, A requiem for the cholecystokinin provocation test?, Gut, 43, 571-574.

[6] Funch-Jensen, P., 1995, Sphincter of Oddi physiology, Journal of Hepato-Biliary-Pancreatic Surgery, 2 , 249-254.

[7] Bingener, J., Richards, M.L., Schwesinger, W.H. and Sirinek, K.R., 2004, Laparoscopic cholecystectomy for biliary dyskinesia, Surgical Endoscopy, 18, 802-806.

[8] Yap, L., Wycherley, A.G., Morphett, A.D. and Toouli, J., 1991, Acalculous biliary pain: cholecystectomy alleviates symptoms in patients with abnormal cholescintigraphy, Gastroenterology, 101, 786-793.

[9] Smythe Ahmed, R., Fitzhenry, M., Johnson, A.G. and Majeed, A.W., 2004, Bethanechol provocation testing does not predict symptom relief after cholecystectomy for acalculous biliary pain, Digestive and Liver Disease, 36, 682-686.

[10] Ness, T.J. and Gebhart, G.F., 1990, Visceral pain: a review of experimental studies, Pain, 41, $167-234$.

[11] Gaensler, E.A., 1951, Quantitative determination of the visceral pain threshold in man, Journal of Clinical Investigation, 30, 406-420.

[12] Csendes, A., Kruse, A., Funch-Jensen, P., Oster, M.J., Ornsholt, J. and Amdrup, E., 1979, Pressure measurements in the biliary and pancreatic duct systems in controls and in patients with gallstones, previous cholecysterctomy, or common bile duct stones, Gastroenterology, 77, 1203-1210.

[13] Drewes, A.M., Pedersen, J., Liu, W., Arendt-Nielsen, L. and Gregersen, H., 2003, Controlled mechanical distension of human oesophagus: sensory and biomechanical findings, Scandinavica Journal of Gastroenterology, 38, 27-35.

[14] Barlow, J.D., Gregersen, H. and Thompson, D.G., 2001, Identification of the biomechanical factors associated with the perception of distension in the human esophagus, American Journal of Physiology, 282, G683-G689.

[15] Petersen, P., Gao, C., Arendt-Nielsen, L., Gregersen, H. and Drewes, A.M., 2003, Pain intensity and biomechanical response during ramp-controlled distension of the human rectum, Digestive Diseases and Sciences, 48(7), 1310-1316. 
[16] Gao, C., Arendt-Nielsen, L., Liu, W., Petersen, P., Drewes, A.M. and Gregersen, H., 2002, Sensory and biomechanical responses to ramp-controlled distension of the human duodenum, American Journal of Physiology, 284, G461-G471.

[17] Gregersen, H., Hausken, T., Yang, J., Odegaard, S. and Giljia, O.H., 2006, Mechanosensory properties in the human gastric antrum evaluated using B-mode ultrasonography during volume-controlled antral distension, American Journal of Physiology, 290, G876-G882.

[18] Cozzolino, H.J., Goldstein, F., Greening, R.R. and Wirts, C.W., 1963, The cystic duct syndrome, JAMA, 185, 920-924.

[19] Majeed, A.W., Smythe, A. and Johnson, A.G., 1994, Continuous in vivo manometry of the human gallbladder, Neurogastroenterology and Motility, 6(2), 162-165.

[20] Dodds, W.J., Hogan, W.J. and Green, J.E., 1989, Motility of the biliary system. In: S.G. Schultz (Ed.) Handbook of Physiology: The Gastrointestinal System (Betheda, Maryland: American Physiological Society), vol. 1, Section 6, Part 2(28), pp. 1055-1101.

[21] Ryan, J. and Cohen, S., 1976, Gallbladder pressure-volume response to gastrointestinal hormones, American Journal of Physiology, 230, 1461-1465.

[22] Fung, Y.C., 1984, Biodynamics Circulation (New York: Springer-Verlag), pp. 22-23.

[23] Middelfart, H.V., Jensen, P., Hojgaard, L. and Funch-Jensen, P., 1998, Pain patterns after distension of the gallbladder in patients with acute cholecystis, Scandinavica Journal of Gastroenterology, 33, 982-987.

[24] Novozhilov, V.V., 1964, Thin Shell Theory (Groningen: P. Noordhoff Ltd), pp. 125-130.

[25] Deitch, E.A., 1981, Uitility and accuracy of ultrasonically measured gallbladder wall as a diagnostic criteria in biliary tract disease, Digestive Diseases and Sciences, 26(8), 686-693.

[26] Matsumoto, T., Sarna, S.K., Condon, R.E., Dodds, W.J. and Mochinaga, N., 1988, Canine gallbladder cyclic motor activity, American Journal of Physiology, 255, G409-G416.

[27] Milenov, K. and Shahbazian, A., 1995, Cholinergic pathways in the effect of motilin on the canine ileum and gallbladder motility: in vivo and in vitro experiments, Comparative Biochemistry Physiology, 112A(3/4), 403-410.

[28] Pitt, H.A., Doty, J.E., DenBesten, L. and Kuchenbecker, S.L., 1981, Stasis before gallstone formation: altered gallbladder compliance or cystic duct resistance, The American Journal of Surgery, 143, 144-149.

[29] Everson, G.T., Braverman, D.Z., Johnson, M.L. and Kern, F., 1980, A critical evaluation of real-time ultrasonography for the study of gallbladder volume and contraction, Gastroenterology, 79, 40-46.

[30] Inglfinger, J.A., Mosteller, F., Thibodeau, L.A. and Ware, J.H., 1987, Biostatistics in Clinical Medicine (New York: Macmillan Publishing Co. Inc.), pp. 140-148.

[31] Dawson-Saunders, B. and Trapp, R.G., 1994, Biostatistics (London: Prentice-Hall International Inc.), pp. $148-149$.

\section{Appendix A: logistic transformation [30,31]}

From elementary statistics, we know that if we have a sample from a normal distribution with known variance $\sigma^{2}$, a $95 \%$ confidence interval for the mean $\mu$ is [31]

$$
\bar{x} \pm 1.96 \frac{\sigma}{\sqrt{n}} .
$$

The quantity $\sigma / \sqrt{n}$ is called the standard error; it measures the variability of the sample mean $\bar{x}$ about the true mean $\mu$. The number 1.96 comes from a table of the standard normal distribution; the area under the standard normal density curve between -1.96 and 1.96 is $95 \%$.

The confidence interval (A1) is valid because over repeated samples the estimate $\bar{x}$ is normally distributed about the true value $\mu$ with a standard deviation of $\sigma / \sqrt{n}$.

When the sample size is small, we may be able to improve the quality of the approximation by applying a suitable reparameterization, a transformation of the parameter to a new scale. The "logistic" or "logit" transformation is such a transformation, defined as

$$
\phi=\log \left(\frac{p}{1-p}\right)
$$


Here, $0 \leq p \leq 1$ and $-\infty<\phi<-\infty$. Solving (A2) for $p$ produces the backtransformation,

$$
p=\frac{\mathrm{e}^{\phi}}{1+\mathrm{e}^{\phi}}
$$

Table A1 shows a $2 \times 2$ contingency table for the two variables $A$ and $B$, with sample sizes $n_{1}$ (success) and $n_{2}$ (failure), and $B$ with sample sizes $n_{3}$ (success) and $n_{4}$ (failure), respectively. We want to determine the endpoints of $95 \%$ confidence interval for success rates $p_{1}$ and $p_{2}$ as well as to compare them. The success rates are calculated from

$$
p_{1}=\frac{n_{1}}{n_{1}+n_{2}}
$$

and

$$
p_{2}=\frac{n_{3}}{n_{3}+n_{4}}
$$

The endpoints of the $95 \%$ confidence intervals for success rate $p_{1}$ are

$$
p_{1 \text { low }}=\frac{\mathrm{e}^{p_{1}-1.96 \sqrt{1 /\left(p_{1}\left(n_{1}+n_{2}\right)\left(1-p_{1}\right)\right)}}}{1+\mathrm{e}^{p_{1}-1.96 \sqrt{1 /\left(p_{1}\left(n_{1}+n_{2}\right)\left(1-p_{1}\right)\right)}}},
$$

and

$$
p_{1 \text { high }}=\frac{\mathrm{e}^{p_{1}+1.96 \sqrt{1 /\left(p_{1}\left(n_{1}+n_{2}\right)\left(1-p_{1}\right)\right)}}}{1+\mathrm{e}^{p_{1}+1.96 \sqrt{1 /\left(p_{1}\left(n_{1}+n_{2}\right)\left(1-p_{1}\right)\right)}}} .
$$

The endpoints of $95 \%$ confidence interval for success rate $p_{2}$ (variable $B$ ) are

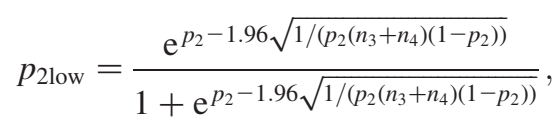

and

$$
p_{\text {2high }}=\frac{\mathrm{e}^{p_{2}+1.96 \sqrt{1 /\left(p_{2}\left(n_{3}+n_{4}\right)\left(1-p_{2}\right)\right)}}}{1+\mathrm{e}^{p_{2}+1.96 \sqrt{1 /\left(p_{2}\left(n_{3}+n_{4}\right)\left(1-p_{2}\right)\right)}}} .
$$

The difference between success rate of $A$ and $B$ can be distinguished by using the ratio of odds from the two rows in table A1. The asymptotic standard error of two samples is [30]

$$
\sigma=\log \left(\sqrt{\frac{1}{n_{1}}+\frac{1}{n_{2}}+\frac{1}{n_{3}}+\frac{1}{n_{4}}}\right),
$$

and the ratio of odds from two samples is [30]

$$
\theta=\log \left[\frac{p_{1}\left(1-p_{2}\right)}{\left(1-p_{1}\right) p_{2}}\right]
$$


Table A1. $2 \times 2$ contingency table for the variables $A$ and $B$.

\begin{tabular}{llcc}
\hline Variable & Success & Failure & Sample size \\
\hline$A$ & $n_{1}\left(p_{1}\right)$ & $n_{2}\left(1-p_{1}\right)$ & $n_{1}+n_{2}$ \\
$B$ & $n_{3}\left(p_{2}\right)$ & $n_{4}\left(1-p_{2}\right)$ & $n_{3}+n_{4}$ \\
\hline
\end{tabular}

The endpoints of 95\% confidence interval for the ratio of odds are [30]

$$
\theta_{\text {low }}=\mathrm{e}^{\theta-1.96 \sigma}
$$

and

$$
\theta_{\text {high }}=\mathrm{e}^{\theta+1.96 \sigma}
$$




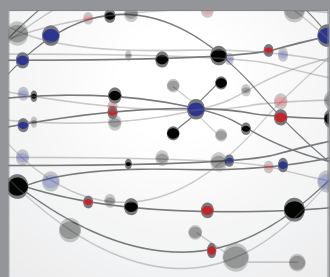

The Scientific World Journal
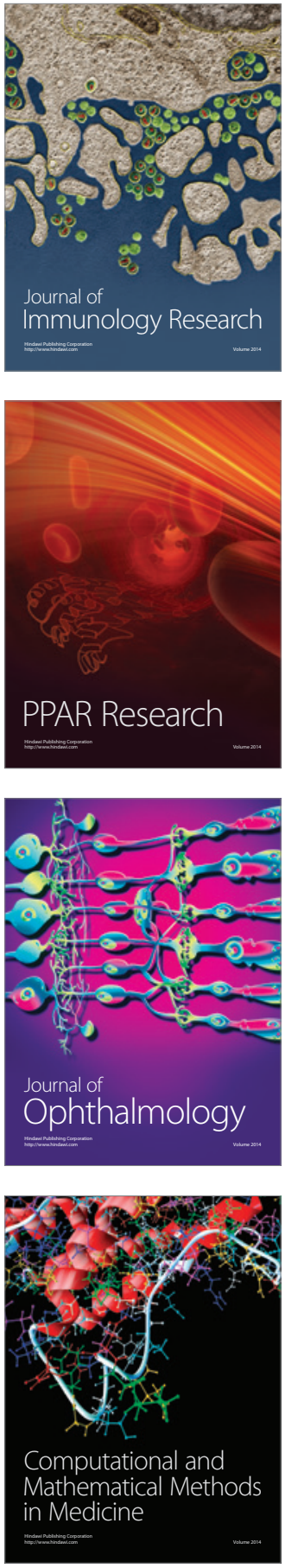

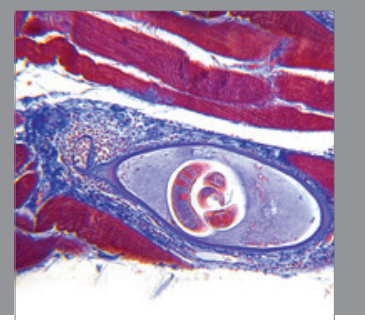

Gastroenterology

Research and Practice
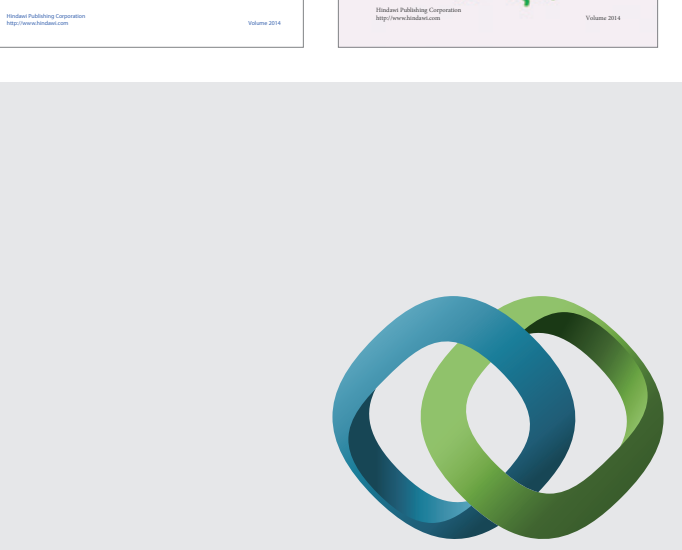

\section{Hindawi}

Submit your manuscripts at

http://www.hindawi.com
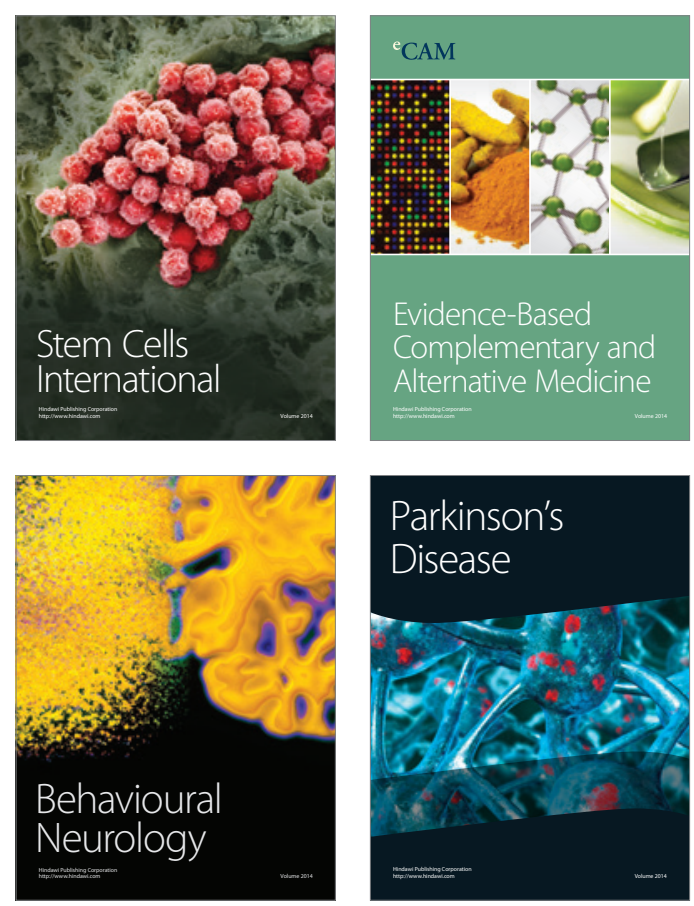

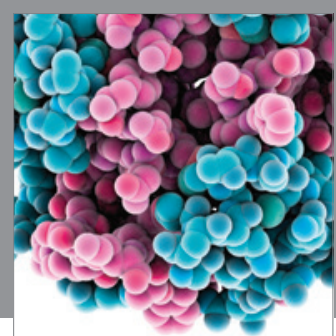

Journal of
Diabetes Research

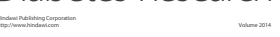

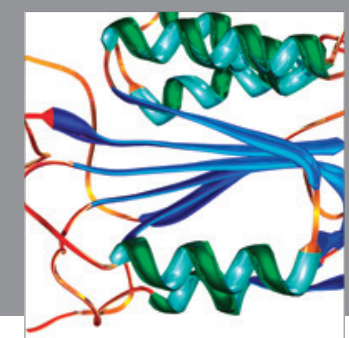

Disease Markers
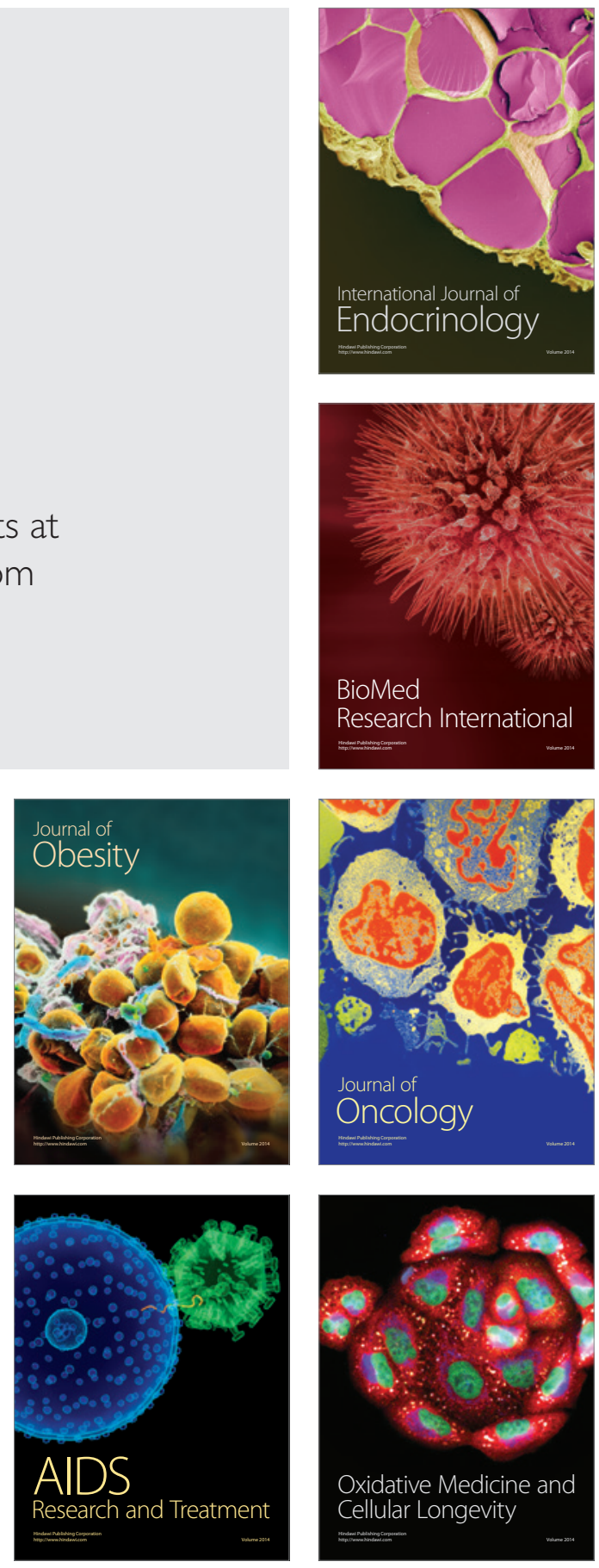